\title{
Academic Performance and Social Competence of Adolescents: Predictions based on Effortful Control and Empathy
}

\author{
Juan P. Zorza ${ }^{1}$, Julián Marino², Soledad de Lemus ${ }^{1}$ and Alberto Acosta Mesas ${ }^{1}$ \\ 1 Universidad de Granada (Spain) \\ ${ }^{2}$ Universidad Nacional de Córdoba (Argentina)
}

\begin{abstract}
This study explored the predictive power of effortful control (EC) on empathy, academic performance, and social competence in adolescents. We obtained self-report measures of EC and dispositional empathy in 359 students (197 girls and 162 boys) aged between 12 and 14 years. Each student provided information about the prosocial behavior of the rest of his/her classmates and completed a sociogram. At the end of the school year, we calculated the mean grade of each student and the teacher responsible for each class completed a questionnaire on the academic skills of his/her students. The study confirmed the existence of a structural equation model (SEM) in which EC directly predicted academic performance and social competence. Additionally, empathic concern partially mediated the effect of EC on social competence. Finally, social competence significantly predicted academic performance. The article discusses the practical applications of the model proposed.
\end{abstract}

Received 29 February 2012; Revised 27 April 2012; Accepted 27 June 2012

Keywords: effortful control, empathy, academic performance, peer relationships.

In Western countries, academic performance and school cohabitation are two major concerns of scientists, citizens, and politicians. Reports are regularly published on students' knowledge at the end of compulsory education (PISA, 2010) and school cohabitation (DíazAguado, Martín, \& Martínez, 2010). These topics have been explored from heterogeneous and multidisciplinary approaches. In the areas of psychology and neuroscience, cognitive development and socio-emotional development have been associated with cognitive control processes (Posner \& Rothbart, 2005), emotional self-regulation, and empathy (Decety \& Svetlova, 2012; Eisenberg, Spinrad, \& Eggum, 2010). There is empirical evidence that individual differences in attentional control influence students' adaptation to both academic and social school demands (Checa, Rodríguez-Bailón, \& Rueda, 2008) and that academic performance and socio-emotional adjustment can be improved by providing training in control and self-regulation skills (Rueda, Checa, \& Rothbart, 2010).

Since children start attending school, they are continually expected to reach curricular goals and develop a broad range of skills that cannot be achieved without

Correspondence concerning this article should be addressed to Alberto Acosta Mesas. Departamento de Psicología Experimental. Facultad de Psicología. Campus Universitario de Cartuja, s/n. 18071. Granada (Spain).

E-mail: acosta@ugr.es

This research was funded by the Junta de Andalucía (Spain) through a research project (P07-SEJ-03299) awarded to the last author. the mediation of the control processes that are part of the executive function. At the same time, in the context of interpersonal relationships with teachers, schoolmates, and parents, students experience many affective and emotional states. Such states must be properly managed and regulated according to the demands of the time and the normative frameworks of the group (Acosta, 2008a). The transition from childhood to adolescence and later to maturity is characterized by the consolidation of personal autonomy and independence. All this progress is mediated by the strengthening of control skills (Crone, 2009).

Many theorists and researchers have found a positive relationship between effortful control (EC) on one side and academic performance and good social adjustment on the other (see reviews by Liew, 2012; Rueda et al., 2010). EC is a basic dimension of temperament that mediates between voluntary control of behavior and regulation of emotional reactivity (Derryberry \& Rothbart, 1997). It is related to the efficiency of executive attention in changing and focusing attention, inhibiting inappropriate behaviors (inhibitory control), activating or performing an action when there is a strong tendency to avoid it (activation control), and with information integration and action planning (Eisenberg, Valiente \& Eggum, 2010). The processes involved in EC partially overlap with those involved in the executive function (Liew, 2012). In fact, EC seems to be mainly supported by some regions of the prefrontal cortex - particularly the anterior cingulate cortex (Posner, Rothbart, Sheese, \& 
Tang, 2007) - that are also part of the neural network that supports executive control.

Some studies have directly predicted academic performance and social behavior from EC. Liew, McTigue, Barrois, and Hughes (2008) obtained measures of effortful control and academic performance from 6-year-old children in a longitudinal study performed during three consecutive years. They found positive correlations between control measures and literacy and math achievement in the first year. Checa et al. (2008) reported that adolescents with better control resources also had higher academic performance, particularly in math, and were preferred by their classmates in sociometric tests. Cermakova, Moneta, and Spada (2010) reported a relationship between self-reported attentional control measures and the learning strategies of a group of college students. They found that students with more control resources organized their time better and used a more elaborate and comprehensive strategy.

Other studies have also explored the possibility that direct relationships between EC and academic performance may be mediated by social behavior. Valiente, Lemery-Chalfant, Swanson, and Reiser (2008) assessed the social skills of children aged between 7 and 12 years based on their participation in class and their relationship with their teachers. They found that children's social skills partially mediated the relationship between children's EC and their mean academic grades at the beginning and the end of the school year. In a subsequent longitudinal study, Valiente et al. (2011) obtained data from a children sample at three different points in time. At the age of 6 years, they assessed children's EC using parents' reports and inhibitory control using a behavioral task. Two years later, they assessed children's social functioning based on reports from parents and teachers. Finally, at the age of 12 years, they included academic performance in their assessments. Using a structural equation model, the authors confirmed that social functioning fully mediated the relationship between EC and academic performance. This relationship was not explained by any other variables such as sex, age, or socio-economic level.

All this evidence highlights the importance of control processes in academic performance and social competence throughout children's development from childhood to late adolescence. However, other dispositions or skills are also particularly relevant in this type of predictions, particularly regarding social behavior. On the one hand, EC has also been associated with empathy (Eisenberg et al., 2007; Valiente et al., 2004). On the other hand, numerous studies have associated empathy with the display of prosocial behavior and the maintenance of a good network of interpersonal relationships (De Waal, 2008; Rimé, 2009).
Empathy refers to individuals' ability to understand and respond to the affective experiences of others (Decety \& Jackson, 2004) and plays a central role in social relationships. It allows two people - or a group of people - to share their affects, understand each other's feelings, show interest in each other's concerns, and often help each other (Singer \& Lamm, 2009). It involves a great deal of interrelated cognitive and affective processes (Shamay-Tsoory, Aharon-Peretz, \& Perry, 2009). The most important of these are 1) empathic concern, which is probably shared with other species (Decety \& Svetlova, 2012) and mediates affective activation, and 2) perspective taking, which makes it possible to consider someone else's point of view. All these processes are deployed when human beings establish links with other people, whether they are strangers, friends, classmates, colleagues, parents, or intimate partners, among others (Singer, 2009). Some of these processes are closely linked to cognitive control (Barkley, 2001). In an empathic situation, the distinction between 'self' and 'other' is maintained and evoked emotions are regulated to prevent emotional overreaction (Decety \& Jackson, 2006). From a neuroanatomical point of view, empathic regulation processes are supported by connections among the orbitofrontal cortex, the medial prefrontal cortex, and the dorsolateral prefrontal cortex (Decety, 2011), which are also mobilized in other circumstances that require cognitive control.

Some studies have explored whether empathy is supported by cognitive control and self-regulation skills. Valiente et al. (2004) found a relationship between EC, dispositional empathy, and situational empathy and discomfort in children aged between 4 and 8 years exposed to video segments. They found that EC was negatively correlated with personal discomfort and positively correlated with children's dispositional empathy. Eisenberg et al. (2007) obtained similar results in a longitudinal study with 6-year-old children assessed every two years, five times in total. In that study, high levels of EC were positively correlated with participants' empathic responses and negatively correlated with participants' impulsiveness.

There is abundant empirical evidence of the relationship between empathy, prosocial behavior, and social skills (Eisenberg, Eggum, \& Di Giunta, 2010). This relationship has been found to persist throughout individuals' development. Eisenberg et al. (1999) published a study in which participants were assessed from the ages of 4 to 22 years, approximately. At early ages, assessments were based on the observation of participants' prosocial behaviors with their classmates and information provided by parents about such behaviors and children's empathic skills. At later ages, the authors administered self-report questionnaires and obtained reports from classmates. Results showed a 
strong continuity in prosocial behavior over time and a close relationship between such behavior and empathy. Spinrad and Eisenberg (2009) also found that students who showed concern about the emotions of others and exhibited prosocial behaviors were better accepted by their schoolmates and more positively rated by adults.

There is currently a growing interest to identify whether the various components of empathy differentially influence social behavior (Batanova \& Loukas, 2011). Caravita, Di Blasio, and Salmivalli (2009) found that the empathic concern of primary and secondary education students was positively correlated with helping behaviors toward victims of bullying, particularly among friends. By contrast, perspective taking in high-status students was associated in some cases with intimidating behaviors toward others. Jolliffe and Farrington (2006) conducted a study with secondary education students. They found that affective empathy, a construct that is equivalent to empathic concern but not to cognitive perspective taking, differentiated between abusive and non-abusive adolescents, regardless of sex. In that study, affective empathy was higher in non-abusive adolescents. Recently, Batanova and Loukas (2011) found that, in 14-year-old adolescents, high levels of empathic concern were negatively correlated with aggressive behaviors exhibited by them one year later. Perspective taking was positively correlated with subtle strategies of control and interpersonal dominance.

The studies described above suggest the existence of close relationships between EC on one side and empathy, academic performance, and social competence on the other. They also highlight the importance of empathic processes in social behavior. However, much less is known about the possible relationships between EC and empathy in the simultaneous prediction of academic performance and interpersonal relationships. EC-related skills are likely to have a general effect on empathy. Yet, the relationship between empathy and academic performance and the mediating effect of EC predictions on interpersonal relationships are not clear.

Eisenberg et al. (2010) proposed two pathways of influence of control processes on academic performance. One pathway links them directly, while the other postulates that academic performance is indirectly influenced through social competence (see Figure 1 part A). On the one hand, effective control processes guarantee a good achievement of academic demands. On the other hand, relationships among peers and between students and teachers and the motivation to participate in school activities also lead to better academic performance when such cognitive control resources are present. Although empirical data (Valiente et al., 2011) confirmed the model in a longitudinal study with children aged between 6 and 12 years, it would be good to corroborate it at older ages or higher educational levels. The first years of secondary school play a key role in adolescents' socialization and future academic performance (Wentzel \& Caldwell, 1997). Between the age of 10 and 12 years, interpersonal relationships increasingly revolve around the peer group and often prevail over family relations. At these ages, a great deal of emotional support comes from peers and personal

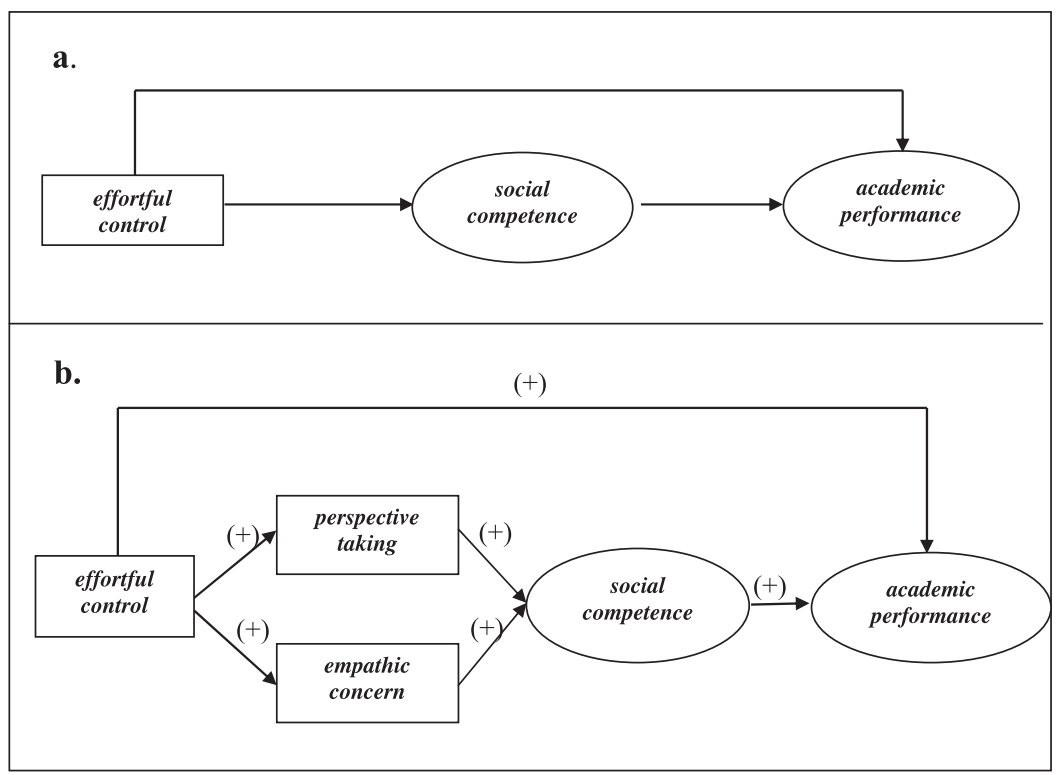

Figure 1. Proposal adapted from Eisenberg, Valiente, and Eggum (2010) on the positive relationships between effortful control, social competence, and academic performance (part A). Model verified in this study (part B) including dispositional empathy as a mediator of the influence of effortful control on social competence. 
identity becomes consolidated in the framework of these relationships (Parker \& Asher, 1993). During adolescence, the relationships between EC, academic performance, and social competence may be different from those observed at earlier ages, particularly the influence of social competence on academic performance. The links between peer relationships and academic performance may be closer during childhood than at later stages.

Given the close relationships between EC and empathy as well as between empathy and prosocial behaviors and good interpersonal relationships, it seems appropriate to include empathy as another relevant construct in the prediction of such relationships. It is important to clarify whether the effects of EC on social competence require the presence of a high level of dispositional empathy or not. EC resources alone are likely to be insufficient to successfully predict social competence without the presence of empathy to link them to the interpersonal sphere.

The aim of this study was to test a predictive model of academic performance during adolescence (see Figure 1 part B). Based on the proposal made by Eisenberg, Spinrad et al. (2010), we expected EC to predict academic performance both directly and through the mediation of social competence. Our main goal was to verify whether peer judgments of both interpersonal preference and prosocial behaviors are positively correlated with academic performance during adolescence, as has been observed at earlier ages. We also hypothesized that the influence of EC on social competence is mediated by adolescents' dispositional empathy. Yet, as explained above, this relationship has been found to differ according to the affective and cognitive components of empathy (Batanova \& Loukas, 2011; Caravita et al., 2009; Jolliffe \& Farrington, 2006). We expected empathic concern to have greater predictive power than perspective taking. The following measures were obtained to test the model: self-report measures of EC and empathy, measures of social competence provided by classmates, and academic performance, computed from teachers' reports and participants' mean grades at the end of the school year (eight months after assessing EC and empathy).

It was decided to test the fit of the model with structural equation modeling (SEM). This method was expected to reveal the functional relationships among the variables and assess the equivalence between the covariance measures derived from the model and those obtained from the data (Bentler, 1988). The aim was not to use such results to draw causal relationships among the variables. Instead, we intended to use the pattern of relationships confirmed among the variables to learn more about the constructs present in the model and to formulate recommendations aimed at improving educational intervention.

\section{Method}

\section{Participants}

The sample consisted of 359 students (197 girls and 162 boys) attending four public secondary education schools in the city of Granada, Spain. Participant age ranged between 12 and 14 years. Mean age was 12.47 years $(S D=.73)$ for girls and 12.50 years $(S D=.74)$ for boys. Students came from families of medium to low socio-economic and cultural status. Participation was voluntary, with the consent of parents.

\section{Questionnaires and measures}

\section{Effortful control}

EC was evaluated using the Early Adolescence Temperament Questionnaire - Revised Self Report (EATQ-R self report; Ellis \& Rothbarth, 2001), translated into Spanish by Checa et al. (2008). In the literature, this scale has been used with adolescent populations from the age of 10 (Ellis \& Rothbart, 2001). The EATQ-R evaluates four factors of temperament in adolescents: 'effortful control', 'extraversion/surgency', 'negative affect', and 'affiliation'. In this study, we used the total score of the 16 items that collected information about 'effortful control' $(\alpha=.69)$, composed of three subfactors: 'activation control' (e.g., "If I have a hard assignment to do, I get started right away"), 'attention' (e.g., "It is easy for me to really concentrate on homework problems"), and 'inhibitory control' (e.g., "I can stick with my plans and goals"). Items were rated on a Likert scale from 1 (almost always untrue of you) to 5 (almost always true of you). In the present study, internal consistency $(\alpha=.73)$ was similar to that reported in previous studies (Valiente et al., 2008).

\section{Empathy}

Empathy was assessed with the Spanish adaptation (Mestre, Frías, \& Samper, 2004) of the Interpersonal Reactivity Index (IRI) (Davis, 1983). This is one of the scales most widely used in the literature as a measure of dispositional empathy. It includes 28 items grouped into four sub-factors: empathic concern, perspective taking, fantasy, and personal distress. As in previous studies (Batanova \& Loukas, 2011; Gini, Albiero, Benelli, \& Altoè, 2007), the present study included scores of perspective taking and empathic concern, the two dimensions that provide the most accurate and direct measurement of empathic resources. The factors fantasy and personal distress have sometimes led to ambiguous interpretations and show low correlations with behavioral and brain activation measures (Decety \& Lamm, 2009). Empathic concern evaluates whether an individual responds affectively to the 
emotional experience of others (e.g., "I often have tender, concerned feelings for people less fortunate than $\left.\mathrm{me}^{\prime \prime}\right)$. Perspective taking provides information about individuals' cognitive ability to see something from someone else's perspective in everyday situations (e.g., "I try to look at everybody's side of a disagreement before I make a decision"). Items were rated on a Likert scale from 1 (does not describe me well) to 5 (describes me very well). In the Spanish version, Mestre et al. (2004) confirmed the factor structure reported by Davis (1983), with internal consistency indices (Empathic Concern: $\alpha=.65$; Perspective Taking: $\alpha=.56$ ) that were similar to those of the present study (Empathic Concern: $\alpha=.59$; Perspective Taking: $\alpha=.63$ ).

\section{Prosocial behaviors}

Following the proposal made by López (2006), an adapted sociogram was used to obtain information about students' prosocial behaviors. Each participant evaluated the extent to which his/her classmates helped him/her in various situations (i.e., schoolwork, sadness or concern, conflict with other schoolmates). Responses were provided on a Likert scale from 1 (not helpful) to 5 (very helpful).

\section{Social preference}

This variable was assessed using the following sociometric procedure: from their class list, students selected the three classmates they would most like to carry out various school or leisure activities with and the three classmates they would least like to carry out these activities with. Following the method proposed by Newcomb, Bukowski, and Patte (1993), each participant's number of positive and negative nominations was divided by the number of students in his/her class. The index of social preference was obtained by subtracting the adjusted score of negative nominations from that of positive nominations. To reduce the number of decimals, 10 was added to the result.

\section{Academic skills}

Teachers completed the Escala de Valoración del Profesor I-S (I-S Teacher Assessment Scale) (Clemente, Albiñana, \& Doménech, 1999), composed of 24 items assessing students' socialization, respect for authority, and intelligence. Each teacher rated his/her students on a scale from 1 (minimum) to 10 (maximum). This study only includes the measures of the sub-factor intelligence, which assesses teachers' perception of their students' academic skills and school readiness (e.g., "their ability to implement what has been learned"). The internal consistency of this factor was very high both in the study sample $(\alpha=.98)$ and that initially used for the original validation of the questionnaire.
Mean grades

Academic performance was measured by calculating each student's mean grades in June, at the end of the school year. The remaining measures were obtained about eight months earlier during the same school year. ${ }^{1}$

\section{Procedure}

Participants were given a booklet in which the selfreport questionnaires were presented in random order. They were informed that the data would be treated confidentially and were given verbal and written instructions on how to complete each questionnaire. The booklets were completed during school hours in a group session that lasted about 40 to 50 minutes in the first term of the school year (October and early November). At the end of the school year, the school management provided a list the final grades of each participant and the teacher responsible for each class completed the scale that assessed students' academic skills.

\section{Results}

\section{Preliminary analyses}

Participants' means and standard deviations for each variable are shown in Table 1. Results of the correlation analysis among them are shown in Table 2. EC was positively correlated with all the other variables, although the highest correlation was found with academic performance and the lowest correlation was found with the index of social preference. Empathy scores also showed positive relationships with academic performance and peer judgments of prosocial behavior. Such judgments and social preference scores were also positively correlated with academic performance scores. As expected, a positive high correlation was found between students' mean grades and their academic skills as rated by their teachers. These correlation patterns suggested that it was appropriate to test the mediation relationships proposed in the model.

\section{Evaluation of the models}

The predictions of the model were tested with structural equation modeling (SEM) using the AMOS statistical package, version 18.0. The high positive correlations

\footnotetext{
${ }^{1}$ To verify that the mean grade was a consistent index of performance that did not fluctuate depending on the school or the teachers, direct scores in each subject were transformed into a $z$ scale and the mean grade was obtained in this scale. Correlations between the mean of the direct grades used in the study and the mean grades on the $z$ scale were .843 . Moreover, the correlations between grades in some subjects such as Natural Science (.889), Social Science (.866), Spanish (.869) and Math (.875) transformed into the $z$ scale and direct mean grades of all subjects were also very high.
} 
Table 1. Means and standard deviations of the measures obtained in the study as a function of gender

\begin{tabular}{|c|c|c|c|c|}
\hline \multirow[b]{2}{*}{ Variables } & \multicolumn{2}{|l|}{ Girls } & \multicolumn{2}{|l|}{ Boys } \\
\hline & $M$ & $S D$ & $M$ & $S D$ \\
\hline Effortful control & 10.64 & 1.64 & 10.36 & 1.52 \\
\hline Perspective taking & 23.89 & 4.78 & 21.59 & 4.44 \\
\hline Empathic concern & 25.67 & 5.20 & 22.98 & 4.54 \\
\hline Prosocial behavior & 3.23 & 0.66 & 2.92 & 0.65 \\
\hline Social preference & 10.03 & 0.12 & 9.99 & 0.15 \\
\hline Mean grades & 6.43 & 1.83 & 5.75 & 1.73 \\
\hline Academic skills & 6.94 & 2.18 & 6.16 & 2.24 \\
\hline
\end{tabular}

found between students' mean grades and their academic skills as rated by their teachers justified the creation of a latent variable for academic performance. Applying the same criterion, another latent variable was created for social competence, composed of peer judgments of prosocial behavior and the index of social preference. Moreover, given that perspective taking and empathic concern are related factors of empathy, a single multidimensional construct, and their measure errors may be related, we added a covariance between the error terms of these variables. The Kolmogorov Smirnov (K-S) test was performed for each of the variables in the model to determine whether the assumption of normality was met. All values were non-significant, which indicates that the assumption was met.

Results of the analysis of Model 1 indicated adequate fit, $\chi^{2}=98.826, d f=10, p=.001 ; \chi^{2} / d f=9.887$; RMSEA = .158 (PCLOSE $=.000)$, CFI $=.902$, NFI $=.893$. As expected, a significant relationship was found between the error terms of perspective taking and empathic concern. As hypothesized, EC positively and significantly predicted academic performance $(\beta=.33, p<.001)$, perspective taking $\left(\beta=.31, p<.001 ; R^{2}=.10\right)$, and empathic concern $\left(\beta=.20, p<.001 ; R^{2}=.04\right)$. The prediction that social competence would influence academic performance was confirmed $(\beta=.43, p<.001)$. Students whose prosocial behaviors were positively rated by their peers and who were chosen by them to perform various schoolrelated activities had higher academic performance. In addition, the predictive relationships of the model revealed the influence of empathy on social competence. social competence was predicted by students' empathic concern $(\beta=.20$, $p<.005)$ but not by perspective taking, the cognitive dimension of empathy $(\beta=.11)$. In Model $\mathrm{A}, \mathrm{EC}$ and dispositional empathy predicted $7 \%$ of the variance in social competence, which in turn predicted $32 \%$ of the variance in academic performance.

The evaluation of the model's modification indices suggested a possible direct relationship between EC and the components of the latent variable social competence. EC is likely to influence social competence not only indirectly through the mediation of empathy but also directly. As explained in the introduction, numerous studies have provided evidence of the positive relationship between EC on one side and social skills and a decrease of behavioral problems among children and adolescents on the other (Eisenberg, Spinrad et al., 2010). Students with high levels of EC are likely to have better school adjustment and be more positively rated by their peers. For these reasons, a parameter considering the direct influence of EC on social competence was included in Model 2. Results of the analysis confirmed that EC directly predicted social competence $(\beta=.19, p<.005)$, empathic concern $(\beta=.20, p<.001$; $\left.R^{2}=.04\right)$, and perspective taking $\left(\beta=.31, p<.001 ; R^{2}=.04\right)$, and academic performance was still influenced by EC $(\beta=.31, p<.001)$ and social competence $(\beta=.42, p<.001)$ (see Figure 2). In addition, they showed a better fit of the model, $\chi^{2}=6.034, d f=9, p=.736 ; \chi^{2} / d f=.670$; RMSEA $=.000($ PCLOSE $=.972), \mathrm{CFI}=1.000, \mathrm{NFI}=$ .993 , which explained $10 \%$ of the variance in social competence and $34 \%$ of the variance in academic performance. A comparison of the models using the chi-square difference test, $\Delta \chi^{2}=10.674, p<.001$, confirmed that Model 2 had better goodness-of-fit indices. Both models were also compared using the Akaike information criterion (AIC, Akaike, 1974).

Table 2. Pearson correlations among the measures obtained in the study

\begin{tabular}{lllllll}
\hline Variables & 2 & 3 & 4 & 5 & 6 & 7 \\
\hline 1. Effortful control & $.31^{* *}$ & $.20^{* *}$ & $.22^{* *}$ & $.24^{* *}$ & $.41^{* *}$ & $.36^{* *}$ \\
2. Perspective taking & - & $.51^{* *}$ & $.19^{* *}$ & .07 & $.21^{* *}$ & $.22^{* *}$ \\
3. Empathic concern & - & - & $.22^{* *}$ & $.12^{*}$ & $.23^{* *}$ & $.23^{* *}$ \\
4. Prosocial behavior & - & - & - & $-52^{* *}$ & $.44^{* *}$ & $.29^{* *}$ \\
5. Social preference & - & - & - & - & - & $.87^{* *}$ \\
6. Mean grades & - & - & - & - & - & - \\
7. Academic skills & - & - & & & - & - \\
\hline
\end{tabular}

${ }^{*} p<.05 ;{ }^{* *} p<.01$. 
The second had a lower AIC than the first one, which shows it had a better fit. ${ }^{2}$

Finally, given the direct influence of EC on social competence and the low predictive power of the latter on perspective taking and empathic concern, we wanted to verify whether the predictive power and fit of the model were adequate when the relation between EC and dispositional empathy was not considered. Consequently, the correlation parameters between EC and the measures of dispositional empathy were removed from Model 3. Results of the analysis showed inadequate fit indices, $\chi^{2}=42.755, d f=11, p=.001 ; \chi^{2} / d f=$ 3.887; RMSEA $=.090($ PCLOSE $=.010)$, CFI $=.965$, $\mathrm{NFI}=.954, \mathrm{AIC}=90.755$, confirming the need to maintain the relationship between EC and dispositional empathy.

In short, Model 2 (see Table 3) had the best fit indices. The hypothesis that EC has a positive influence on academic performance both directly and indirectly through the mediation of social competence was confirmed in this model. In addition, EC seems to influence social competence both directly and through the mediation of empathic concern (see Figure 2). To assess the mediation of empathic concern, we assessed the indirect conditional effect of EC on social competence using the bias corrected and accelerated (BCa) Bootstrapping method with 2000 resamples (Preacher \& Hayes, 2008). The effect of EC on empathic concern (a path) was $\beta=.64, p<$ $.001, t=3.811(p<.001, d f=350)$, the direct effect of empathic concern on social competence (b path) was $\beta=.03$, $p<.001, t=3.115(p<.005, d f=350)$, the total effect of EC on social competence (c path) was $\beta=.12, p<.001, t=$ $3.660(p<.0005, d f=350)$, and the direct effect of EC on social competence ( $c^{\prime}$ path) was $\beta=.09, p<.005, t=3.009$ $(p<.005, d f=350)$. The Sobel test, which assumes normality for indirect effects, indicated significant values for the $a b$ path, $\mathrm{z}=2.45, p<0.01$, whereas the BCa method obtained a significant confidence interval, between 0.009 and 0.04 (95\%). These results suggest the existence of partial mediation. Although the total effect was low, it remained significant when controlled by the mediator. This confirms that EC has direct and indirect effects (mediated by empathic concern) on the prediction of social competence in adolescents.

A multi-group SEM was performed to assess whether gender was a moderator in Model 2. This was done because some differences were found between

\footnotetext{
${ }^{2}$ In this model, predictions of Perspective Taking and Empathic Concern on Social Competence were independent. These two measures had moderate reliability, partly because of the formative nature of the scales. Therefore, to ensure the consistency of the prediction of Empathy on Social Competence, a latent variable was created for empathy, composed of these two measures. The results of the analysis also confirmed the adequate fit of the model, $\chi^{2}=10,58, \mathrm{~d} f=10, p=.39$; $\chi^{2} / d f=1.05 ; \mathrm{RMSEA}=.01(\mathrm{PCLOSE}=.88), \mathrm{CFI}=.99, \mathrm{NFI}=.98$.
}

the mean scores of boys and girls and there is controversy about the influence of gender on academic performance (Valiente et al., 2008). We computed another model where we forced the loadings of each factor, regressions, and covariates so that they would be the same in both groups. There is no moderation if an equivalence is found between boys and girls (Byrne, 2001). The resulting model showed adequate fit, $\chi^{2}=$ 31.280, $d f=28, p=.305 ; \chi^{2} / d f=1.117 ;$ RMSEA $=.018$ $(\mathrm{PCLOSE}=.974), \mathrm{CFI}=.996, \mathrm{NFI}=.965$. The difference in $\chi^{2}$ (15.711), with 10 degrees of freedom, was not significant $(p=.108)$, which shows that the proposed model is fit both for girls and boys between 12 and 14 years.

\section{Discussion}

Results confirmed the influence of cognitive control processes on academic skills and performance (Eisenberg, Valiente, \& Eggum, 2010; Rueda et al., 2010). Most research in this area has focused on children or has taken the form of longitudinal studies with children from 6 to 12 years (Valiente et al., 2011), neglecting older ages or higher education levels. One of our main objectives was to find out whether EC remains a direct determining factor on the academic performance of adolescents from 12 to 14 years attending secondary education. This was confirmed by our results. We also wanted to explore whether the indirect influence of EC through social competence is mediated by dispositional empathy. This hypothesis was also confirmed.

The relationship between voluntary control of behavior and good academic performance in adolescents may be the result of two factors: EC promotes the skills needed for good learning but also encourages behaviors that facilitate an adequate response to academic demands. Attentional control, one of the components of EC, promotes the cognitive processes that are necessary for good learning. Students' ability to focus on the relevant aspects of academic contents as well as their flexibility when manipulating mental representations and performing complex reasoning tasks is likely to facilitate their understanding and performance at school (Rueda et al., 2010).

Attentional control is known to influence cognitive processes that are key for learning. In addition, we also believe adolescents high in EC have good academic performance because they have good academic habits and ongoing motivation for achievement. It should be noted that the present study not only assessed academic performance using students' mean grades but included a measure of the teacher's opinion on each student's academic skills. This ensured a broader and multi-dimensional assessment of academic performance, as recommended in this type of studies 
Table 3. Fit indices for each model assessed with structural equation modeling

\begin{tabular}{lrrrrrrr}
\hline & \multicolumn{1}{c}{$\chi^{2}$} & $d f$ & CFI & NFI & RMSEA & AIC & $\Delta \chi^{2}$ \\
\hline Model 1 & 16.71 & 10 & .99 & .98 & .04 & 66.71 & $10.67^{*}$ \\
Model 2 & 6.03 & 9 & 1.00 & .99 & .00 & 58.03 & $36.72^{*}$ \\
Model 3 & $42.75^{*}$ & 11 & .96 & .95 & .09 & 90.75 & 36 \\
\hline
\end{tabular}

Note: $d f$ = Degrees of freedom; CFI = Comparative Fit Index; NFI = Bentler-Bonett Normed Fit Index; RMSEA= Root Mean Square Error of Approximation; $A I C=$ Akaike information criterion. $\Delta \chi^{2}$ decrease in Model 2 compared to models 1 and 3 , respectively.

${ }^{*} p<.05$.

(Eisenberg, Valiente et al., 2010). In the questionnaire, the teacher reported whether the student paid attention in class, did his/her homework, and had a good disposition for learning, among other issues. Results showed a positive correlation between EC and all these behaviors. Activation control and inhibitory control, two components of EC, are key for students to be able to organize, plan, and maintain the behaviors that contribute to good learning and performance, and to inhibit their tendency to exhibit distractive behaviors. The literature has reported that students with adequate EC levels respond positively to school demands, use better learning strategies (Cermakova et al., 2010), participate in class, and are more committed to school (Eisenberg, Valiente et al., 2010; Valiente et al., 2008). By contrast, students low in EC often cannot adapt to the rules and functioning of schools, increase the negative perception of their performance, lose motivation, and exhibit disruptive behaviors (Eisenberg, Valiente et al., 2010).

As hypothesized, supporting the model proposed by Eisenberg et al. (2010), we obtained evidence that the effect of EC on academic performance is not only direct but also indirect and mediated by social competence. Recent studies with children have confirmed that EC leads to better academic performance by improving students' interpersonal relationships with peers and teachers and increasing their participation in class (Valiente et al., 2008). Our study obtained evidence that, during early adolescence, EC also predicts prosocial behaviors and peer acceptance and social competence also plays a relevant role in the prediction of academic performance. Control resources are likely to facilitate the compliance of relationship rules of the peer group and the school itself, contributing to maintaining the links between adolescents and academic interest. Our results agree with those of other studies (Wentzel, 2003) that have shown a better performance in students who are accepted and feel they are members of the peer group than those who are ignored or rejected. Group exclusion or problems with peer relationships can have a negative influence on students' interest and participation in class, reducing their academic motivation.

Our results partially confirm the prediction that dispositional empathy mediates the effect of EC on social behavior. The model with the best fit showed a direct influence of EC on social competence and an indirect influence mediated by empathy. The fit disappeared when the relationship between EC and empathy was

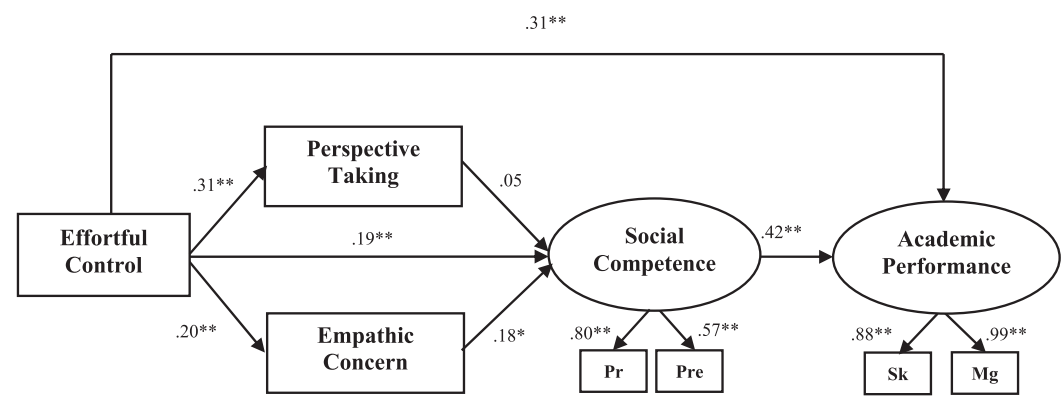

Figure 2. Verified structural equation model considering the influence of effortful control, empathic concern, perspective taking, and social competence on academic performance. $\chi^{2}=6.03, d f=9, p=.74 ; \chi^{2} / d f=.67 ; \mathrm{RMSEA}=.000(\mathrm{PCLOSE}=.97), \mathrm{CFI}=1.000, \mathrm{NFI}=.99$. The model explained $34 \%$ of the variance in Academic Performance.

Pr: Peer judgments of prosocial behavior. Pre: Index of social preference. Sk: Academic skills assessed by the teacher. Mg: Mean grade of all the subjects taken by the student. ${ }^{*} p<0.05 ;{ }^{* *} p<0.01$. 
not considered (Model 3). This shows the need to consider the relationship between EC and dispositional empathy in the prediction of students' social behavior. This relationship confirms that control and empathic processes are jointly mobilized in the interpersonal domain (Decety \& Svetlova, 2012; Eisenberg et al., 2007; Lamm, Batson, \& Decety, 2007). Emotional self-regulation may also be of great relevance in this framework of relationships (Eisenberg \& Eggum, 2009; Lamm et al., 2007). Future studies should provide more insight on this matter.

As hypothesized and in accordance with previous studies (Caravita et al., 2009; Gini et al., 2007), empathic concern was found to significantly predict social competence, whereas perspective taking did not. The ability to adopt the perspective of others and understand their affects does not necessarily lead to prosocial behaviors (Jolliffe \& Farrington, 2006; Batanova \& Loukas, 2011). These results should be used when developing intervention strategies to prevent violence and bullying. Promoting only the cognitive elements of empathy without getting students to experiment emotional states does not seem to be enough to foster non-violent or prosocial behaviors.

Results indicate that predictive relationships are not moderated by gender. Data on EC were similar to those obtained by Valiente et al. (2011). These authors also found that the effect of EC on academic performance and social competence was independent of student gender. As regards empathy, the literature has often attributed greater empathic resources and a closer relationship between dispositional empathy and prosocial behavior to older girls (Wentzel, Baker, \& Russell, 2009). This data pattern was also observed in our sample. Girls obtained slightly higher scores in empathy and prosocial behavior than boys. However, the model was not moderated by this variable. Relationships among empathy, interpersonal behavior, and gender are complex (Decety \& Svetlova, 2012). Different results have been reported depending on the age of participants and the method use to assess empathy (Garaigordobil, 2009) or the relevant interpersonal behavior measured. Jolliffe and Farrington (2006) found that adolescent girls with low empathy scores exhibited indirect bullying behaviors, but this relationship was not observed in boys. In boys, lower affective empathy resources were associated with direct physical or verbal abuse. From a practical perspective, this finding suggests that interventions aimed at strengthening positive interpersonal relationships among adolescents should be based on promoting empathy, particularly its affective elements, but also general behavioral control skills. Among boys, who usually have more limited empathic resources than girls, activities and habits aimed at consolidating these control processes would be particularly valuable.

One of the limitations of our study is the fact that the EC and empathy measures were only assessed with self-reports. As far as possible, these processes and skills should be assessed with behavioral measures and information provided by peers, family members, and/or teachers to ensure they have greater validity and robustness. In any case, the correlation patterns among these measures and between them and measures of academic performance and social competence as well as the results of the models compared granted them considerable robustness.

Results of this study can be useful to design intervention programs aimed at improving academic performance and school cohabitation. Given the relevance of EC in the prediction of academic performance, we recommend that students with attention difficulties receive training to strengthen attentional control and executive functions. Various studies have found improvements in concentration and intelligence after such interventions (Klingberg, Forssberg, \& Westerberg, 2002). Moreover, training should begin at an early age (Rueda et al., 2004). As discussed by Posner and Rothbart (2005), the executive attention network plays a key role in school activities and demands. Yet, this relationship often goes unnoticed. Families and teachers should systematize and adjust their demands to ensure that, from an early age, children start to develop the habits and skills that make up the executive functions and provide individuals with the necessary resources to tackle school demands successfully.

Furthermore, the relationship between EC and empathy and the influence of both on social competence and of the latter on academic performance suggest that interventions that address these three areas are better than those restricted to one of them. Self-regulation should be promoted not only from an intra-individual approach but also in social situations that allow including empathic processes and interpersonal demands (Wentzel et al., 2009). Social behavior and personal objectives gradually develop around the acquisition of solid and stable moral criteria based on the ability to understand one's own emotions and thoughts as well as those of others (Eisenberg, 2000). Experiences of blame and shame and their good management in the interpersonal domain and play a key role in regulation of social behavior, compliance with regulatory frameworks, and the prevention of violent behaviors (Tangney, Stuewig, \& Mashek, 2007) and require empathic processes. Individuals' ability to manage emotional and behavioral responses in harmony with the needs of others and the compromises of being part of a group are necessary to achieve the "moral reciprocity" required for a peaceful coexistence (Ortega, 2007). 
Programs specifically aimed at promoting empathy and self-regulation (Solomon, Battistich, Watson, Schaps, \& Lewis, 2000; Spinrad \& Eisenberg, 2009) have sometimes been opposed to those that recommend more comprehensive educational actions addressing these issues as well as academic ones (Eisenberg et al., 2010). Our results suggest that a framework of positive interpersonal relationships and a good atmosphere in class and at school contribute to good academic performance. Schools should systematically try to ensure the academic curriculum is met and promote a good social climate that facilitates its achievement. It seems unnecessary to focus concerns exclusively on progress in declarative knowledge about the various subjects. It is also important to provide spaces and resources for socio-emotional learning. This can accommodate recent concerns about the acquisition of emotion understanding and regulating skills as well as more traditional activities dealing with academic motivation, democratic management of rules and values, and regulation of interpersonal conflict (Acosta, 2008b).

Finally, the results of the study support the development of educational actions promoting the use of autonomy, independence, and self-control resources to maintain a positive framework of interpersonal relationships and social climate in the classroom and promote good academic performance as well.

\section{References}

Acosta A. (2008a). La educación de los sentimientos y la convivencia escolar [Education of feelings and school life]. In M. Soler Villalobos (Ed.), De la Educación Socioemocional a la Educación en Valores [From socioemotional education to ethic education] (pp. 31-52). Madrid, Spain: Ministerio de Educación y Ciencia.

Acosta A. (2008b). La educación emocional y la convivencia en el aula [Emotional education and coexistence in the clasroom]. In A. Acosta (Coord.), Educación emocional y convivencia en el aula [Socioemotional education and cohabitation in classroom] (pp. 11-30). Madrid, Spain: Ministerio de Educación.

Akaike H. (1974). A new look at the statistical model identification. IEEE Transactions on Automatic Control, 19, 716-723. http:/ / dx.doi.org/10.1109/TAC.1974.1100705

Barkley R. A. (2001). The executive functions and self-regulation: An evolutionary neuropsychological perspective. Neuropsychology Review, 11, 1-29. http:/ /dx. doi.org/10.1023/A:1009085417776

Batanova M. D., \& Loukas A. (2011). Social anxiety and aggression in early adolescents: Examining the moderating roles of empathic concern and perspective taking. Journal of Youth and Adolescence, 40, 1534-1543. http:/ / dx.doi.org/ 10.1007\%2Fs10964-011-9634-x

Bentler P. M. (1988). Causal modeling via structural equation systems. In J. R. Nesselroade \& R. B. Catell (Eds.), Handbook of multivariate experimental psychology, $\left(2^{\text {nd }}\right.$ ed. pp. 317-335). New York, NY: Plenum Press.
Byrne B. (2001). Structural equation modeling with Amos: Basic concepts, applications and programming. New Jersey, NJ: Lawrence Erlbaum Associates.

Caravita S. C. S., Di Blasio P., \& Salmivalli C. (2009). Unique and interactive effects of empathy and social status on involvement in bullying. Social Development, 18, 140-163. http://dx.doi.org/10.1111/j.1467-9507. 2008.00465.x

Cermakova L., Moneta G. B., \& Spada M. M. (2010). Dispositional flow as a mediator of the relationships between attentional control and approaches to studying during academic examination preparation. Educational Psychology, 30, 495-511. http:/ / dx.doi.org/10.1080\% 2F01443411003777697

Clemente A., Albiñana P., \& Doménech F. (1999). Escala de Valoración del Profesor I-S [Teacher Assessment Scale I-S]. Anales de Psicología, 15, 233-238.

Crone E. A. (2009). Executive functions in adolescence: Inferences from brain and behavior. Developmental Science, 12, 825-830. http:/ /dx.doi.org/10.1111/j.1467-7687.2009.00918.x

Checa P., Rodríguez-Bailón R., \& Rueda M. R. (2008). Neurocognitive and temperamental systems of selfregulation and early adolescents' social and academic outcomes. Mind, Brain, and Education, 2, 177-187. http:/ / dx.doi.org/10.1111/j.1751-228X.2008.00052.x

Davis M. H. (1983). Measuring individual differences in empathy: Evidence for a multidimensional approach. Journal of Personality and Social Psychology, 44, 113-126. http:/ /dx.doi.org/10.1037\%2F0022-3514.44.1.113

De Waal F. B. M. (2008). Putting the altruism back into altruism: The evolution of empathy. Annual Review of Psychology, 59, 279-300. http:/ / dx.doi.org/10.1146/ annurev.psych.59.103006.093625

Decety J. (2011). Dissecting the neural mechanisms mediating empathy. Emotion Review, 3, 92-108. http://dx. doi.org/10.1177/1754073910374662

Decety J., \& Jackson P. L. (2004). The functional architecture of human empathy. Behavioral and cognitive neuroscience reviews, 3, 71-100. http:/ /dx.doi.org/10.1177/ 1534582304267187

Decety J., \& Jackson P. L. (2006). A social-neuroscience perspective on empathy. Current Directions in Psychological Science, 15, 54-58. http://dx.doi.org/10.1111/ j.0963-7214.2006.00406.x

Decety J., \& Lamm C. (2009). Empathy versus personal distress: Recent evidence from social neuroscience. In J. Decety \& W. Ickes (Eds.), The social neuroscience of empathy (pp. 199-215). Cambridge, MA: MIT Press.

Decety J., \& Svetlova M. (2012). Putting together phylogenetic and ontogenetic perspectives on empathy. Developmental Cognitive Neuroscience, 2, 1-24. http:/ / dx. doi.org/10.1016/j.den.2011.05.003

Derryberry D., \& Rothbart M. K. (1997). Reactive and effortful processes in the organization of temperament. Development and Psychopathology, 9, 633-652. http://dx. doi.org/10.1017\%2FS0954579497001375

Díaz-Aguado M., Martín J., \& Martínez R. (2010). Estudio estatal sobre la convivencia escolar en la educación secundaria obligatoria. [National study on school cohabitation in secondary schools]. Madrid, Spain: Ministerio de 
Educación. Retrieved from http:/ /sede.educacion.gob.es / publiventa/detalle.action? $\operatorname{cod}=13567$

Eisenberg N. (2000). Emotion, regulation, and moral development. Annual Review of Psychology, 51, 665-697. http:/ / dx.doi.org/10.1146\%2Fannurev.psych.51.1.665

Eisenberg N., \& Eggum N. D. (2009). Empathic responding: Sympathy and personal distress. In J. Decety \& W. Ickes (Eds.), The social neuroscience of empathy. Cambridge, MA: MIT Press.

Eisenberg N., Eggum N. D., \& Di Giunta L. (2010). Empathy-related responding: Associations with prosocial behavior, aggression, and intergroup relations. Social Issues and Policy Review, 4, 143-180. http:/ /dx.doi.org/ 10.1111\%2Fj.1751-2409.2010.01020.x

Eisenberg N., Guthrie I. K., Murphy B. C., Shepard S. A., Cumberland A., \& Carlo G. (1999). Consistency and development of prosocial dispositions: A longitudinal study. Child Development, 70, 1360-1372. http:/ / dx.doi.org /10.1111\%2F1467-8624.00100

Eisenberg N., Michalik N., Spinrad T. L., Hofer C., Kupfer A., \& Valiente C. (2007). The relations of effortful control and impulsivity to children's sympathy: A longitudinal study. Cognitive Development, 22, 544-567. http:/ /dx.doi.org/10.1016\%2Fj.cogdev.2007. 08.003

Eisenberg N., Spinrad T. L., \& Eggum N. D. (2010). Emotion-related self-regulation and its relation to children's maladjustment. Annual Review of Clinical Psychology, 6, 495-525. http://dx.doi.org/10.1146/ annurev.clinpsy.121208.131208

Eisenberg N., Valiente C., \& Eggum N. D. (2010). Self-regulation and school readiness. Early Education and Development, 21, 681-698. http://dx.doi.org/10.1080\% 2F10409289.2010.497451

Ellis L. K., \& Rothbart M. K. (2001, October). Revision of the early adolescent temperament questionnaire. Poster presented at the 2001 Biennial Meeting of the Society for Research in Child Development, Minneapolis, MN.

Gini G., Albiero P., Benelli B., \& Altoè G. (2007). Does empathy predict adolescents' bullying and defending behavior? Aggressive Behavior, 33, 467-476. http:/ /dx.doi. org/10.1002/ab.20204

Garaigordobil M. (2009). A comparative analysis of empathy in childhood and adolescence: Gender differences and associated socio-emotional variables. International Journal of Psychology and Psychological Therapy, 9, 217-235.

Jolliffe D., \& Farrington D. P. (2006). Examining the relationship between low empathy and bullying. Aggressive Behavior, 32, 540-550. http:/ / dx.doi.org/10.1002/ab.20154

Klingberg T., Forssberg H., \& Westerberg H. (2002). Training of working memory in children with ADHD. Journal of Clinical and Experimental Neuropsychology, 24, 781-791. http:/ /dx.doi.org/10.1076\%2Fjcen.24.6.781.8395

Lamm C., Batson C. D., \& Decety J. (2007). The neural substrate of human empathy: Effects of perspective-taking and cognitive appraisal. Journal of Cognitive Neuroscience, 19, 42-58. http:/ /dx.doi.org/10.1162/jocn.2007.19.1.42

Liew J. (2012). Effortful control, executive functions, and education: Bringing self-regulatory and social-emotional competencies to the table. Child Development Perspectives,
6, 105-111. http:/ /dx.doi.org/10.1111/j.1750-8606. 2011.00196.x

Liew J., McTigue E. M., Barrois L., \& Hughes J. N. (2008). Adaptive and effortful control and academic self-efficacy beliefs on achievement: A longitudinal study of 1st through $3^{\text {rd }}$ graders. Early Childhood Research Quarterly, 23, 515-526. http://dx.doi.org/10.1016/j.ecresq.2008.07.003

López F. (2006). El bienestar personal y social y la prevención del malestar y la violencia [Personal and social wellbeing and prevention of discomfort and violence]. Madrid, Spain: Pirámide.

Mestre V., Frías M. D., \& Samper P. (2004). La medida de la empatía: Análisis del interpersonal reactivity index [Measuring empathy: Analysis of the interpersonal reactivity index], Psicothema, 16, 255-260.

Newcomb A. F., Bukowski W. M., \& Pattee L. (1993). Children's peer relations: A meta-analytic review of popular, rejected, neglected, controversial, and average sociometric status. Psychological Bulletin, 113, 99-128. http:/ / dx.doi.org/10.1037\%2F0033-2909.113.1.99

Ortega R. (2007). La convivencia: Un regalo de la cultura a la escuela [Cohabitation: A gift from culture to schools]. Revista de Educación de Castilla la Mancha, 4, 50-54.

Parker J. G., \& Asher S. R. (1993). Friendship and friendship quality in middle childhood: Links with peer group acceptance and feelings of loneliness and social dissatisfaction. Developmental Psychology, 29, 611-621. http:/ / dx.doi.org/10.1037\%2F0012-1649.29.4.611

PISA. OECD. (2010). Programa para la evaluación internacional de los alumnos [Programme for International Student Assessment]. Spanish Repport. Madrid, Spain: Ministerio de Educación. Retrieved from http:/ / iaqse.caib. es/documents/aval2009-10/pisa2009-informe-espanol.pdf

Posner M. I., \& Rothbart M. K. (2005). Influencing brain networks: Implications for education. Trends in Cognitive Sciences, 9, 99-103. http:/ /dx.doi.org/10.1016\%2Fj.tics. 2005.01.007

Posner M. I., Rothbart M. K., Sheese B. E., \& Tang Y. (2007). The anterior cingulate gyrus and the mechanism of self-regulation. Cognitive, Affective and Behavioral Neuroscience, 7, 391-395. http://dx.doi.org/10.3758\%2FCABN.7.4.391

Preacher K., \& Hayes A. (2008). Asymptotic and resampling strategies for assessing and comparing indirect effects in multiple mediator models. Behavior Research Methods, 40, 879-891. http:/ / dx.doi.org/10.3758/brm.40.3.879

Rimé B. (2009). Emotion elicits the social sharing of emotion: Theory and empirical review. Emotion Review, 1, 60-85. http:/ / dx.doi.org/10.1177/1754073908097189

Rueda M. R., Checa P., \& Rothbart M. K. (2010). Contributions of attentional control to socioemotional and academic development. Early Education and Development, 21, 744-764. http:/ /dx.doi.org/10.1080/10409289.2010.510055

Rueda M. R., Fan J., McCandliss B. D., Halparin J. D., Gruber D. B., \& Lercari L. P. (2004). Development of attentional networks in childhood. Neuropsychologia, 42, 1029-1040. http:/ /dx.doi.org/10.1016\%2Fj. neuropsychologia.2003.12.012

Shamay-Tsoory S. G., Aharon-Peretz J., \& Perry D. (2009). Two systems for empathy: A double dissociation between emotional and cognitive empathy in inferior frontal gyrus 
versus ventromedial prefrontal lesions. Brain, 132, 617-627. http:/ /dx.doi.org/10.1093/brain/awn279

Singer T. (2009). Understanding others: Brain mechanisms of theory of mind and empathy. In W. G. Paul, F. C. Colin, F. Ernst, P. Russell, \& A. Poldrack (Eds.), Neuroeconomics (pp. 251-268). London, UK: Academic Press.

Singer T., \& Lamm C. (2009). The social neuroscience of empathy. Annals of the New York Academy of Sciences, 1156, 81-96. http:/ /dx.doi.org/10.1111/j.1749-6632.2009.04418.x

Solomon D., Battistich V., Watson M., Schaps E., \& Lewis C. (2000). A six-district study of educational change: Direct and mediated effects of the child development project. Social Psychology of Education, 4, 3-51. http:/ /dx.doi.org/ 10.1023/A:1009609606692

Spinrad T., \& Eisenberg N. (2009). Empathy, prosocial behavior, and positive development in schools. In R. Gilman, E. Huebner, \& M. Furlong (Eds.), Handboof of Positive Psychology in Schools (pp. 119-131). New York, NY: Routledge.

Tangney J. P., Stuewig J., \& Mashek D. J. (2007). Moral emotions and moral behavior. Annual Review of Psychology, 58, 345-372. http:/ / dx.doi.org/10.1146\%2Fannurev. psych.56.091103.070145

Valiente C., Eisenberg N., Fabes R. A., Shepard S. A., Cumberland A., \& Losoya S. H. (2004). Prediction of children's empathy-related responding from their effortful control and parents' expressivity. Developmental Psychology, 40, 911-926. http:/ /dx.doi.org/10.1037\%2F0012-1649. 40.6.911

Valiente C., Eisenberg N., Haugen R., Spinrad T. L., Hofer C., \& Liew J. (2011). Children's effortful control and academic achievement: Mediation through social functioning. Early Education and Development, 22, 411-433. http:/ /dx.doi.org/10.1080/10409289.2010.505259

Valiente C., Lemery-Chalfant K., Swanson J., \& Reiser M. (2008). Prediction of children's cademic competence from their effortful control, relationships, and classroom participation. Journal of Educational Psychology, 100, 67-77. http:/ /dx.doi.org/10.1037/0022-0663.100.1.67

Wentzel K. (2003). Sociometric status and adjustment in middle school: A longitudinal study. Journal of Early Adolescence, 23, 5-28. http://dx.doi.org/10.1177/ 0272431602239128

Wentzel K., Baker S., \& Russell S. (2009). Peer relationships and positive adjustment at school. In R. Gilman \& M. J. Furlong (Eds.) Routledge (Ed.), Handbook of positive psychology in schools (pp. 229-243). New York, NY: Routledge.

Wentzel K., \& Caldwell K. (1997). Friendships, peer acceptance, and group membership: Relations to academic achievement in middle school. Child Development, 68, 1198-1209. http://dx.doi.org/10.2307\%2F1132301 